Open Access

\title{
Social media in undergraduate learning: categories and characteristics
}

\author{
Erika E. Smith
}

\section{Correspondence:}

eesmith@mtroyal.ca

Faculty Development Consultant

Academic Development Centre,

Mount Royal University, Room

T110G, 4825 Mount Royal Gate SW,

Calgary, AB T3E 6K6, Canada

\begin{abstract}
This study investigates the core categories and characteristics of the social media technologies (SMTs) that undergraduate students choose to use in their own learning, outside of the formal curriculum. Within a mixed method research methodology, this inquiry employed 30 semi-structured interviews and an online survey $(N=679)$ to explore why and how undergraduates across disciplines view SMTs to be a meaningful part of their own university learning. Together, the qualitative and quantitative results demonstrate that several contextual relationships exist, including an important relationship between the particular ways of meaning making students identified and the specific social media technologies they use for their university learning. While no differences were found for general social media use, there is a significant relationship between particular ways of making meaning and use of specific SMTs, indicating the importance of learning context and social media affordances.
\end{abstract}

\section{Introduction}

Those concerned with teaching and learning in higher education and the Net generation's perspectives on and uses of technology must address calls to move beyond the digital native debate (Bennett \& Maton, 2010; Kennedy, Judd, Dalgarno, \& Waycott, 2010) by asking students directly what they see as a meaningful part of their learning. Digital native arguments are often used as a warrant for adoption and integration of emerging web technologies, particularly social media technologies (SMTs) that fall under this umbrella of emerging technologies, in higher education settings (Smith, 2012; 2016a). This study aims to move beyond the digital native debate by developing research-informed understandings of the ways in which Net generation students may perceive technologies, specifically social media, to be a meaningful part of their undergraduate learning. By investigating the core categories and characteristics of the social media technologies (SMTs) that undergraduate students choose to use in their learning, we can address the need for contemporary educational research that builds deeper understanding of students' perspectives and uses of social media in their learning. Hamid, Waycott, Kurnia, and Chang (2015) stress the importance of addressing such gaps in the literature, stating that "...detailed analyses of student perspectives covering a range of learning settings are less common....little is known about how students feel about the interactivity benefits of social technologies" (p. 2). This study aims to address such existing research gaps by investigating why and how undergraduate learners view social media technologies to be a meaningful part of their university learning, from the learners' perspective.

(c) The Author(s). 2017 Open Access This article is distributed under the terms of the Creative Commons Attribution 4.0 International License (http://creativecommons.org/licenses/by/4.0/), which permits unrestricted use, distribution, and reproduction in any medium, provided you give appropriate credit to the original author(s) and the source, provide a link to the Creative Commons license, and indicate if changes were made. 
Using a mixed method research methodology, this inquiry employed 30 semistructured interviews and online survey $(N=679)$ to explore why and how undergraduates across disciplines view SMTs to be a meaningful part of their own university learning. Together, results from the semi-structured interviews and the survey show an important relationship between the particular ways of meaning making students identified and the specific social media technologies they use for their university learning. While no differences were found for general social media use, there is a significant relationship between particular ways of making meaning and use of specific SMTs, indicating the importance of learning context and social media affordances.

Social media technologies that fall under this umbrella of emerging web technologies are increasingly adopted in higher education settings (Dron \& Anderson). However, as Saeed, Yun, and Sinnappan (2009) have stated, although the adoption of these technologies is on the rise in academic settings, a major obstacle remains to be "the limited understanding of learners' characteristics and perceptions about technology use" (p. 98). As such, the picture of what technologies students view to be a meaningful part of their academic studies, and specifically which SMTs they choose to use for their learning, is murky. Further contributing to this murkiness, a 2012 study of undergraduates from the EDUCAUSE Center for Applied Research (ECAR) showed that $75 \%$ of students indicated that technology helps them achieve their academic outcomes. However, when asked about SMTs, a majority of students indicated they preferred faceto-face communication with their instructors (Dahlstrom, 2012). In 2012, 57\% of students reported that they prefer to keep their academic and social lives separate, and these numbers have increased:

In $2014,73 \%$ of students agreed or strongly agreed that they like to keep their academic and social lives separate. This is up from 60\% in 2013 and provides context for why just one in three students said they wish their instructors would use social media as a learning tool more, fewer than those who said they wish their instructors would use it less. (Dahlstrom \& Bichsel, 2014, p. 12)

Other recent studies have demonstrated students' separation of academic and social spheres, especially concerning technologies (Jones, Blackey, Fitzgibbon, \& Chew, 2010), though further research is required to understand the reasons why and how this separation occurs, and how it impacts students' perceptions and uses of social media for learning (Smith, 2016a; 2016b).

Such contradictory evidence makes it difficult to know the reasons why students may view particular technologies to be meaningful to their learning, and why they may separate certain SMTs from their academic lives. These contradictions continue in other recent findings, including an ECAR report that showed fewer than $50 \%$ of students indicated using social media as a learning tool (Dahlstrom, Brooks, Grajek, \& Reeves, 2015, p. 25). A strong resistance to social media in learning has also been reported in Canadian contexts, with a recent study from Dalhousie University's Centre for Teaching and Learning reporting that a "majority of teachers $(62.63 \%)$ were in disagreement with the use of these [social media] tools, which was similar to the students' response (66.32\%)" (Sehatzadeh \& Le-May Sheffield, 2014, p. 17). Given widespread news coverage of social media in higher education, such as the media coverage of a troubling Dalhousie dentistry student Facebook group called the Class of DDS 2015 
Gentlemen (CBC News, 2015), it is clear that students, educators, and administrators in post-secondary institutions alike are aware of widespread Facebook use in higher education, even if there is some reluctance to include social media in the formal curricula.

Since research findings show that students can and often do have positive perceptions of technologies in academic settings, while at the same time noting the negative aspects of SMTs and the need to be selective about communication modes to connect to instructors and other students, EDUCAUSE recommends that institutions should "understand which innovations they [students] value the most" (Dahlstrom, 2012, p. 4). A key finding from ECAR's recent undergraduate IT study shows that "meaningful and intuitive use of technology for academics cannot be assumed, even when a technology is widely available or used by students in other contexts" (Dahlstrom et al., 2015, p. 6). To this end, the purpose of the study is to understand student perspectives and selfreported uses of SMTs in meaningful ways for their learning. By further investigating the reasons why students may or may not choose to use social media for learning, educators and administrators can make informed decisions when choosing whether or not to integrate social media in educational practice.

\section{Meaning in education and technology}

Mezirow's (1991) seminal work on transformative learning has been influential in regard to constructivist discussions of meaning and meaning making: "Our actions toward things are based on the meaning that the things have for us. These meanings are handled in and modified through an interpretive process that we use in dealing with the things we encounter" (pp. xiv). In addition to such educational discussions, several authors have engaged with the term meaning as it relates to technologies. For instance, Postman (1992) discusses meaning in regard to technology, warning against reductionism:

Machines cannot feel and, just as important, cannot understand.... It is meaning, not utterance, that makes mind unique....As I understand it, meaning also includes those things we call feelings, experiences, sensations that do not have to be, and sometimes cannot be, put into symbols. They "mean" nonetheless. (emphasis in original,

pp. 112-113)

In this way, human meaning differs from the logic processes and computer languages upon which our technologies are based. Human meaning making involves understandings, communication, and interactions that relate to and represent feelings, emotions, experiences, and values developed within ourselves and through interactions with other people. Meaning makers may mediate and share these experiences through the use of technologies, such as social media, but to give meaning and bring understanding is an inherently human (rather than technological) process.

\section{Affordances of social media for learning}

Throughout this study, undergraduates across disciplines often described social media as "a real double-edged sword" that can either help or hinder learning depending on the context, purpose, or intention of the interaction - in other words, depending on what can be afforded by the technology (Smith, 2016a; 2016b). Willcockson and Phelps (2010) have defined an affordance as "the way a technology or software can be used 
and what it allows the user to do or not to do" (para. 9). Thus, an affordance can be understood as that which is made available (or, suggested) by characteristics that enable one to carry out possible (inter)actions via an object within a physical or virtual environment. For instance, having the ability to click or press an on-screen button via a mouse, trackpad, or touchscreen affords moving through space when navigating in the on-screen environment (Hayman \& Smith, 2015; Smith \& Hayman, 2016). Researchers have called for anti-determinist approaches to educational technology research by (re)focusing on affordances, arguing that such approaches should be emphasized in academic analyses of education, technology, and young people (Buckingham, 2011; Selwyn, 2012). Such approaches to research of technologies in educational contexts can develop a shared understanding of the wider contexts within which technologies are ascribed meaning.

\section{Social media definitions and terms}

Kennedy et al. (2009) have determined that "[m]any emerging Internet technologies can be broadly grouped together under the label 'Web 2.0', an umbrella term used to describe web-based applications, including social software tools" (p. 10). This study uses the term social media as a broad umbrella, with social media technologies (SMTs) used to describe specific platforms or tools (e.g., Facebook). Herrington, Reeves, and Oliver (2010) have described social media as emerging technologies and cognitive tools that "allow the creation of collaborative, shared knowledge...and the development of participatory cultures" (p. 9). As outlined in the survey instrument (see Additional file 1), the following definition was used in the study: Social media include applications and websites that allow users to create and share content. Social media also enable users to connect via web technologies or to participate in social networks. Following Valtonen, Dillon, Hacklin, and Vaisanen's (2010) discussion of social software, 13 updated categories of social media (with SMT examples) in learning were utilized, validated, and refined during the study, as shown in Table 1:

\section{Theoretical framework and research methodology}

This study uses a constructivist approach, a theoretical lens recognizing knowledge to be "constructed by learners as they attempt to make sense of their experiences"

Table 1 Categories of Social Media Investigated

\begin{tabular}{ll}
\hline Categories of Social Media & Example Social Media Technologies \\
\hline Blogs & Blogger, WordPress \\
Wikis & Wikipedia, Wikimedia \\
Google Apps & Google Calendar, Google Docs \\
Image sharing & Flickr, Instagram, Pinterest \\
Social bookmarking & Delicious \\
Social networking & Facebook, Google+ \\
Social news sites & Reddit \\
VOIP \& Instant messaging & Skype, Google talk/chat \\
Do-it-yourself networks & Ning \\
File sharing & Dropbox, Google Drive, BitTorrent \\
Video sharing & YouTube, Vine \\
Location-based applications & Foursquare, Google Maps \\
Microblogs & Twitter \\
\hline
\end{tabular}


(Driscoll, 2005, p. 387). As such, it is founded upon two main constructivist premises: (1) learners actively construct their own knowledge, and (2) social interactions are an important part of knowledge construction (Woolfolk, Winne, Perry, \& Shapka, 2010, pp. 343-344). More specifically, the researcher used social constructivism, understanding knowledge to be constructed via social negotiation by engaging multiple perspectives and experiences (Driscoll, 2005). Social constructivist research frameworks emphasize multiple and varied meanings (Creswell, 2014); therefore, the participants' meanings, views, and perspectives are the focus of inquiry. Social constructivism was also a fit for the study because the alignment between the affordances of social media and the premises of social constructivist learning theories are well established (Dron \& Anderson, 2014).

In alignment with the social constructivist framing of the study, questions within the study (see Smith, 2016a) reflect the following key characteristics of social constructivism as outlined by Woo and Reeves (2007):

- Active construction of knowledge based on experience with and previous knowledge of the physical and social worlds;

- Emphasis on the need for the ZPD (here referred to as communication with peers or experts related to real life, to reflect participants' language);

- Emphasis on the influence of human culture and the sociocultural context;

- Recognition of the social construction of knowledge through dialogue and negotiation;

- Emphasis on the intersubjective construction of knowledge;

- Multiple interpretations of knowledge. (Jaworski, 1994; Ernest, 1995, as cited in Woo \& Reeves, 2007, p. 19)

\section{Methodology}

Mixed methods research (MMR) was used as a methodological umbrella, where methods are intentionally combined in order to best address the research questions (Creswell, 2014). Using an exploratory MMR design, the study involved a first phase qualitative component where the researcher conducted 30 semi-structured interviews, followed by a second phase quantitative component where the researcher conducted an online survey $(N=679)$ of undergraduates across disciplines. Institutional Research Ethics Board (REB) approval was obtained. Following their participation, participants could choose to be entered in a draw for one of four \$25 iTunes gift cards (two for the interview group and two for the survey group), in recognition of their time.

\section{Research methods}

The study's first phase included semi-structured interviews, where generic qualitative strategies (Merriam, 2009) and constructivist grounded theory (CGT) (Charmaz, 2014) techniques were used, including intensive interviewing, constant comparison methods (e.g., comparing data at each stage of analysis), coding techniques (e.g., incident-withincident, focused, and thematic coding), memo-writing, and member checks with interview participants. A semi-structured interview guide was employed (see Smith, 2016a for the complete guide), and interview audio files were subsequently transcribed. Qualitative analysis was conducted via the NVivo software application, and as a part of anonymizing 
the data, pseudonyms have been used to protect the identities of all interview participants. Qualitative results formed a rich, thick description (Cohen, Manion, \& Morrison, 2011) of the themes and patterns of the undergraduates' perceptions and self-reported uses of SMTs in their university learning. Following this interview phase, a subsequent survey phase was conducted to further investigate themes of meaning making and social media use emerging from this initial qualitative phase.

The study's second phase utilized an online survey, collecting responses in SurveyMonkey via a cross-sectional design, to enable macro-level analysis and comparison of different groups (Cohen et al., 2011). Responses were analyzed using statistical procedures via the Statistical Package for Social Sciences (SPSS) software. Reliability and validity were ensured throughout; for example, through thorough consideration of the interview phase and analysis of the research literature, including modifying and updating components of Valtonen et al.s (2010) categories of social software. To develop a high quality instrument, two pilot surveys were analyzed prior to the final survey. An initial pilot survey $(N=22$, Cronbach's alpha of 0.88 ) was conducted with volunteer participants following their interview, with a second pilot survey $(N=15$, Cronbach's alpha of 0.90$)$ conducted with volunteer undergraduates outside of the qualitative sample. The final survey $(N=679$, Cronbach's alpha of 0.92) used primarily closed questions, but also some open-ended questions (see Additional file 1 for the full survey instrument). Items with Likert-type rating scales ranged from 1 (strongly agree) to 5 (strongly disagree). Descriptive analysis was conducted to analyze closed responses, aligned with the nature of the sample. Openended textual responses were analyzed using parallel generic qualitative and CGT techniques (e.g., coding, constant comparison) employed for the interview analysis. Data analysis focused on participant descriptions regarding the categories and characteristics of meaning making and social media in their learning, as well as any notable differences, relationships, or patterns.

\section{Sample}

To achieve saturation of student participants, the qualitative sample was purposeful and homogenous, involving 30 full-time undergraduates at a large Canadian researchintensive university, the University of Alberta, who were between the ages of 18-25 years old. Ten students were interviewed from each of the following disciplinary groups: (1) social sciences and humanities, (2) health sciences, and (3) natural sciences and engineering. The online survey was distributed via a university email list, using a convenience sample. These sampling approaches were effective in achieving saturation of interview data for the first phase, and gathering a robust number of survey responses for the second phase.

\section{Limitations}

This study was designed to address the research questions within the context of a large research-intensive institution in Western Canada. Since this study's focus was on undergraduate students at the University of Alberta, the nature of the samples (a purposeful homogenous sample for the interviews, and a non-probability convenience sample for the survey) is a limitation in regard to the wider transferability and generalizability of the findings (Cohen et al., 2011). Finally, participation of females $(N=442,68.6 \%)$ in the survey was slightly higher than the overall percentage of females (59\% in 2011) in the Canadian undergraduate population (Statistics Canada, 2011). 


\section{Results}

The qualitative and quantitative results illustrate why and how undergraduate ways of making meaning and their specific social media use are related, demonstrating that a significant relationship exists between undergraduate meaning making and the specific SMTs (see Fig. 1) students indicated using in their own university learning. While this article focuses on the core categories and characteristics of social media demonstrated in the survey responses with supporting examples and evidence from the interviews, a detailed discussion of additional qualitative and quantitative findings that are outside of the scope of this article can be found in Smith (2016a; 2016b). The results presented here from the interview and survey data illustrate not only what SMTs undergraduates most often indicated used, but also why students' meaning making activities have an important connection to technologies and learning in this regard.

\section{Social media and meaning making in undergraduate learning}

A particularly valuable outcome of the interview process was the refinement and validation of categories and characteristics of social media for undergraduate learning. At the beginning of the semi-structured interviews, undergraduate students were asked to describe what social media means to them, including associated characteristics and examples. Participants provided a useful set of articulations defining social media characteristics and purposes, and an outline of the most common SMTs they used in their learning. This qualitative discussion, including descriptions regarding the ways in social media help or hinder learning (see Smith, 2016a; 2016b), informed the following core social media characteristics in university learning that were further investigated via the survey: collaborating (e.g., to create documents online); sharing information online; tracking and managing schedules; building relationships (i.e., mainly with peers, occasionally with instructors); posting/re-posting media or information found; and, commenting on media or information found online.

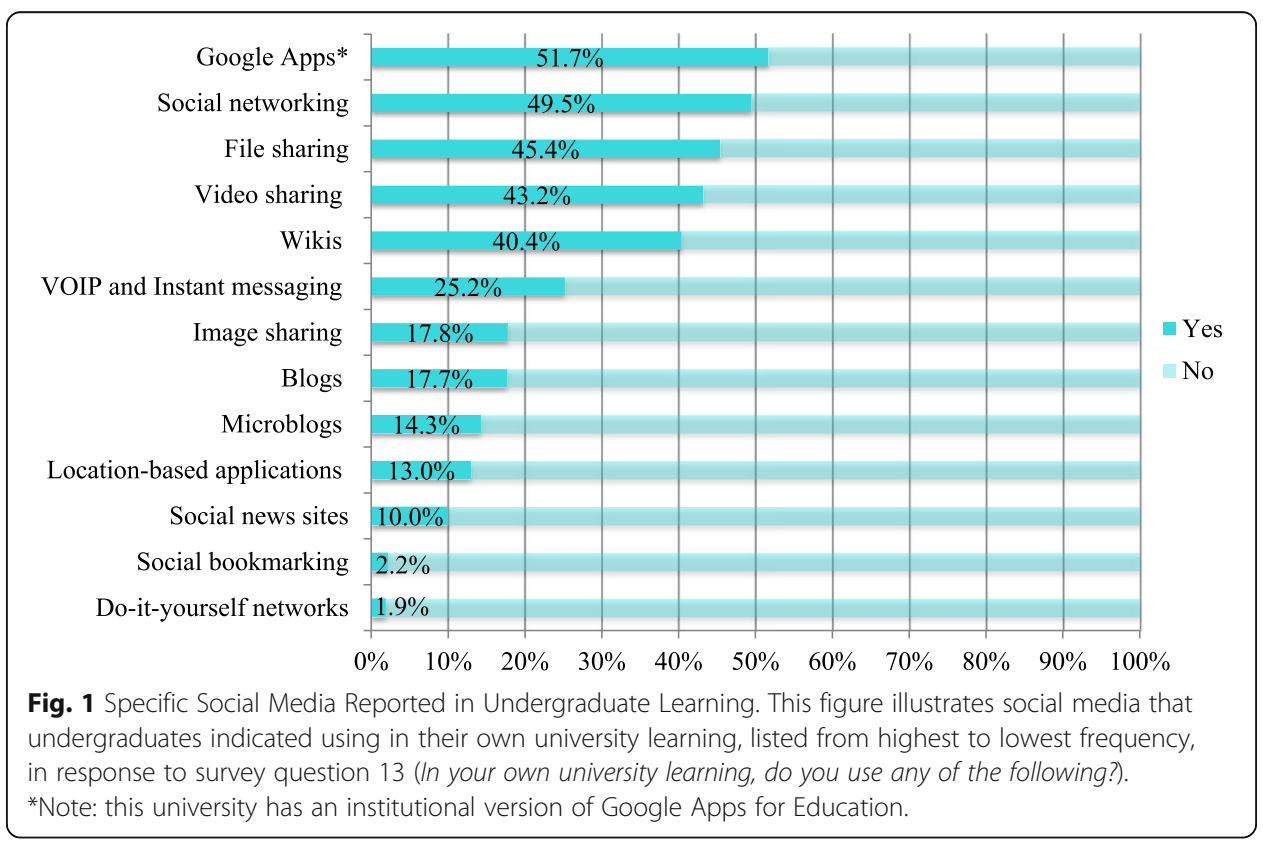


After discussing social media in their university contexts, students were also asked whether they used any of the specific SMTs within or beyond the updated categories of social media in Table 1. As part of this constructive process, interviews with undergraduate students provided the validation and refinement of the categories and characteristics of social media subsequently used in the survey instrument. Through this validation and refinement process, the exclusion of certain social categories beyond specific SMTs became necessary: social games, virtual worlds, email, and feed readers were deemed to be outside of social media in undergraduate learning. To prevent duplication, professional networks (e.g., LinkedIn) were captured under the category of social networks. Some students provided descriptions of eClass (i.e., the LMS) during their interviews, often questioning whether eClass should be considered social media. Overall interview descriptions demonstrated that LMS and web-conferences are most often used for instructor-led rather than student-led interactions, and have distinct parameters and features differing them from social media platforms. This confirmed exclusion of these items (the LMS and web conferencing) from the categories of social media for learning. Meaning making and social media descriptions in the qualitative phase were a critical part not only of the interview component, but also of survey instrument creation and validation, which probed and confirmed themes related to SMTs and meaning making via the online survey (Smith, 2016a).

Although ways of making meaning are often tacitly held and therefore may be difficult to articulate, students participating in the study offered many thoughtful reflections on the importance of meaning making during the interviews. Several students articulated the importance of meaning making in university. For instance, as third year Arts student Joseph stated, "I think in general, meaning making is something that every student is up against in order to make sense of new knowledge and new learning that comes with being in university." Similarly, as second year Arts student Hillary noted, "I think it's one of the main goals of getting a university education is to make meaning of the world around you." Several participants recognized meaning making as something that all students face and as an important goal of university learning. From the interview phase, students described nine core categories of meaning making in university learning (see Table 2). Following these qualitative descriptions, in their survey responses, students indicated the following ways of making meaning of their university learning (listed from highest to lowest frequency).

Table 2 Q10: How do you make meaning ("make sense") of your university learning?

\begin{tabular}{lll}
\hline Variables (highest to lowest frequency) & Yes & No \\
& $n(\%)$ & $n(\%)$ \\
\hline Ways of making meaning & & \\
Gaining your own deep understanding & $501(73.8)$ & $178(26.2)$ \\
Applying your experience to real life & $431(63.5)$ & $248(36.5)$ \\
Working through the process of figuring something out & $426(62.7)$ & $253(37.3)$ \\
Putting your learning into context & $382(56.3)$ & $324(47.7)$ \\
Saying something in your own words & $355(52.3)$ & $356(52.4)$ \\
Interacting with different perspectives & $323(47.6)$ & $358(52.7)$ \\
Researching information & $321(47.3)$ & $311(45.8)$ \\
Discussing with other people & $368(45.8)$ & $422(62.2)$ \\
Seeking help from others & $257(37.8)$ & \\
\hline
\end{tabular}


Even though meaning making is a core tenet of constructivism, frequently used in education and research, few studies provide an analysis of undergraduate perceptions of making meaning in their own learning. Understanding the ways in which undergraduates define and view meaning making in their learning, particularly as these descriptions connect to their choices to use or not use certain social media technologies, helps to provide important context for the reasons why students use certain SMTs over others for their learning.

\section{Social media use and characteristics}

With few exceptions, the majority of students interviewed indicated use of social media in their own university learning, and the majority of survey respondents $(n=451$, $71.5 \%$ ) also indicated using social media in their university learning. Students who use social media in their learning indicated that the most frequently used SMTs (see Fig. 1) closely mirror those perceived to have the highest importance in learning (see Table 3).

For those who indicated using social media in their learning, in terms of usefulness for university, the social media characteristics that received a high number of strongly agree and agree ratings (see Table 4) included:

- Collaborating to create documents online (e.g., Google Docs) (92.4\%)

- Sharing information online (e.g., links to websites, articles) (91.2\%)

- Tracking and managing your academic schedule (88.2\%)

- Building relationships with peers (e.g., Facebook, LinkedIn) (87.0\%)

Table 3 Q14: In your opinion, do you see these social media as an important part of your university learning?

\begin{tabular}{llllll}
\hline & $n$ (percent) & & & & \\
\cline { 2 - 6 } & Strongly agree & Agree & Neutral & Disagree & Strongly disagree \\
\hline Blogs (e.g., Blogger, WordPress) & $18(4.2)$ & $94(22.0)$ & $159(37.2)$ & $102(23.9)$ & $54(12.6)$ \\
Wikis (e.g., Wikimedia) & $131(30.7)$ & $163(38.2)$ & $82(19.2)$ & $35(8.2)$ & $16(3.7)$ \\
$\begin{array}{l}\text { Google Apps (e.g., Google Calendar, } \\
\text { Google Docs) }\end{array}$ & $187(43.1)$ & $162(37.3)$ & $59(13.6)$ & $16(3.7)$ & $10(2.3)$ \\
$\begin{array}{l}\text { Image sharing (e.g., Flickr, Instagram, } \\
\text { Pinterest) }\end{array}$ & $19(4.4)$ & $78(18.2)$ & $162(37.8)$ & $98(22.8)$ & $72(16.8)$ \\
$\begin{array}{l}\text { Social bookmarking (e.g., Delicious) } \\
\text { Social networking (e.g., Facebook, }\end{array}$ & $8(1.9)$ & $24(5.7)$ & $189(44.6)$ & $117(27.6)$ & $86(20.3)$ \\
Google+) & $72(16.7)$ & $179(41.4)$ & $107(24.8)$ & $46(10.6)$ & $28(6.5)$ \\
Social news sites (e.g., Reddit) & $18(4.3)$ & $86(20.3)$ & $168(39.7)$ & $92(21.7)$ & $59(13.9)$ \\
$\begin{array}{l}\text { VOIP and Instant messaging } \\
\text { (e.g., Skype, Google Talk, WhatsApp) }\end{array}$ & $57(13.3)$ & $151(35.4)$ & $143(33.5)$ & $45(10.5)$ & $31(7.3)$ \\
$\begin{array}{l}\text { Do-it-yourself networks (e.g., Ning) } \\
\text { File sharing (e.g., Dropbox, Google }\end{array}$ & $8(1.9)$ & $38(9.1)$ & $222(53.2)$ & $79(18.9)$ & $70(16.8)$ \\
Drive, BitTorrent) & $211(49.2)$ & $150(35.0)$ & $54(12.6)$ & $9(2.1)$ & $5(1.2)$ \\
Video sharing (e.g., YouTube, Vine) & $142(32.9)$ & $182(42.2)$ & $70(16.2)$ & $25(5.8)$ & $12(2.8)$ \\
Location-based applications & $22(5.2)$ & $72(17.1)$ & $180(42.8)$ & $88(20.9)$ & $59(14.0)$ \\
(e.g., Foursquare, Google Maps) & & & & & \\
Microblogs (e.g., Twitter) & $19(4.5)$ & $67(16.0)$ & $155(36.9)$ & $106(25.2)$ & $73(17.4)$ \\
\hline
\end{tabular}


Table 4 Q15: In your opinion, are the following characteristics of social media useful for your university learning?

\begin{tabular}{llllll}
\hline & $n$ (percent) & & & & \\
\cline { 2 - 6 } & Strongly agree & Agree & Neutral & Disagree & Strongly disagree \\
\hline $\begin{array}{l}\text { Building relationships with peers } \\
\text { (e.g., Facebook, Linkedln) }\end{array}$ & $171(40.1)$ & $200(46.9)$ & $39(9.2)$ & $11(2.6)$ & $5(1.2)$ \\
$\begin{array}{l}\text { Building relationships with instructors } \\
\text { (e.g., Facebook, Linkedln) }\end{array}$ & $55(12.9)$ & $146(34.4)$ & $127(29.9)$ & $67(15.8)$ & $30(7.1)$ \\
$\begin{array}{l}\text { Creating media to share online } \\
\text { (e.g., pictures, videos, music) }\end{array}$ & $73(17.2)$ & $198(46.7)$ & $96(22.6)$ & $43(10.1)$ & $14(3.3)$ \\
$\begin{array}{l}\text { Sharing information online } \\
\text { (e.g., links to websites, articles) }\end{array}$ & $187(44.4)$ & $197(46.8)$ & $22(5.2)$ & $12(2.9)$ & $3(0.7)$ \\
$\begin{array}{l}\text { Posting/Re-posting media or } \\
\text { information found online } \\
\text { (e.g., re-tweeting, sharing links) }\end{array}$ & $113(26.9)$ & $188(44.8)$ & $79(18.8)$ & $33(7.9)$ & $7(1.7)$ \\
$\begin{array}{l}\text { Commenting on media or information } \\
\text { found online }\end{array}$ & $65(15.5)$ & $170(40.5)$ & $115(27.4)$ & $60(14.3)$ & $10(2.4)$ \\
$\begin{array}{l}\text { Collaborating to create documents } \\
\text { online (e.g., Google Docs) }\end{array}$ & $249(59.0)$ & $141(33.4)$ & $24(5.7)$ & $7(1.7)$ & $1(0.2)$ \\
$\begin{array}{l}\text { Tracking and managing your academic } \\
\text { schedule }\end{array}$ & $223(52.7)$ & $150(35.5)$ & $36(8.5)$ & $11(2.6)$ & $3(0.7)$ \\
\hline
\end{tabular}

When asked whether certain characteristics of SMTs help in making meaning of university learning (see Table 5), students reported similar ratings for these social media characteristics, though with somewhat lower overall percentages:

- Collaborating to create documents online (e.g., Google Docs) (83.2\%)

- Sharing information online (e.g., links to websites, articles) (81.7\%)

- Building relationships with peers (e.g., Facebook, LinkedIn) (75.2\%)

- Tracking and managing your academic schedule (74.3\%)

Table 5 Q16: In your opinion, do the following characteristics of social media help you to make meaning (make sense) of your university learning?

\begin{tabular}{llllll}
\hline & $n$ (percent) & & & & \\
\cline { 2 - 6 } & Strongly agree & Agree & Neutral & Disagree & Strongly disagree \\
\hline $\begin{array}{l}\text { Building relationships with peers } \\
\text { (e.g., Facebook, Linkedln) }\end{array}$ & $127(30.0)$ & $191(45.2)$ & $62(14.7)$ & $37(8.7)$ & $6(1.4)$ \\
$\begin{array}{l}\text { Building relationships with instructors } \\
\text { (e.g., Facebook, Linkedln) }\end{array}$ & $60(14.3)$ & $144(34.2)$ & $115(27.3)$ & $76(18.1)$ & $26(6.2)$ \\
$\begin{array}{l}\text { Creating media to share online } \\
\text { (e.g., pictures, videos, music) }\end{array}$ & $71(16.9)$ & $168(40.0)$ & $111(26.4)$ & $54(12.9)$ & $16(3.8)$ \\
$\begin{array}{l}\text { Sharing information online } \\
\text { (e.g., links to websites, articles) }\end{array}$ & $127(30.2)$ & $217(51.5)$ & $56(13.3)$ & $16(3.8)$ & $5(1.2)$ \\
$\begin{array}{l}\text { Posting/Re-posting media or } \\
\text { information found online } \\
\text { (e.g., re-tweeting, sharing links) }\end{array}$ & $78(18.5)$ & $176(41.8)$ & $114(27.1)$ & $40(9.5)$ & $13(3.1)$ \\
$\begin{array}{l}\text { Commenting on media or information } \\
\text { found online }\end{array}$ & $59(14.0)$ & $144(34.3)$ & $144(34.3)$ & $55(13.1)$ & $18(4.3)$ \\
$\begin{array}{l}\text { Collaborating to create documents } \\
\text { online (e.g., Google Docs) }\end{array}$ & $187(44.3)$ & $164(38.9)$ & $54(12.8)$ & $11(2.6)$ & $6(1.4)$ \\
$\begin{array}{l}\text { Tracking and managing your academic } \\
\text { schedule }\end{array}$ & $144(34.2)$ & $169(40.1)$ & $77(18.3)$ & $25(5.9)$ & $6(1.4)$ \\
\hline
\end{tabular}




\section{Ways of making meaning and specific social media technologies}

In terms of making meaning, a higher percentage of respondents indicated making sense of their university learning individually (personally) $(n=293,46.4 \%)$ or both individually (personally) and with others (socially) $(n=306,48.4 \%)$, rather than solely with others (socially) $(n=33,5.2 \%)$. Furthermore, analysis of the responses for (Q10) ways of meaning making and (Q13) specific SMT use revealed several relationships, as shown in Tables 6, 7, and 8. Applying a Pearson correlation for ways of making meaning (Q10 totals) and specific SMTs (Q13 totals) revealed a fair degree of relationship (Colton, 1974) and statistical significance: $r(677)=0.38, p<0.001$. The importance and implications of these relationships are detailed in the discussion section, below.

\section{Summary of results}

These findings further reinforce social constructivist connections between social interactions and meaning making in university learning. While social media use in general remains relatively constant across participants, when examining specific ways of meaning making and specific social media use in university learning, several key relationships become evident. As shown through the Pearson correlation, there is a significant relationship between ways of making meaning and specific SMT use, demonstrating not only the connections between meaning making and SMTs, but also that these contexts are important for social media in university learning. There are also connections between particular ways of making meaning and several specific social media, as outlined in the supporting data provided in Tables 6, 7, and 8.

\section{Discussion}

The connections outlined in the qualitative and quantitative results bring forth a range of social media related to making meaning of university learning, presenting a much fuller picture of the nature and purpose of SMTs in learning than can be witnessed in traditional usage data alone. There were associations between specific SMTs used and ways of making meaning, with the most popular SMTs - Google Apps, social networking, file sharing, video sharing, and wikis - also having the highest number of connections with specific activities across the nine core categories of meaning making. The reasons why students used these particular SMTs relate not only to the meaning making activities identified, but also to what is afforded by certain social media characteristics; for example, whether an SMT enables collaborating to create documents online (e.g., Google Docs), sharing information online (e.g., links to websites, articles), tracking and managing an academic schedule, building relationships with peers (e.g., Facebook, LinkedIn), and so on.

As an example of such connections between specific SMTs and meaning making, while wikis were the fifth most used SMT as reported by $40.4 \%$ of students (see Fig. 1), further analysis of the results illustrated that those who indicated using wikis also reported engaging in several meaning making activities in their learning (outlined in Table 6). Reflecting key characteristics of social constructivism (Woo \& Reeves, 2007), these particular ways of making meaning include gaining a deep understanding (82.1\%), discussing with other people (67.2\%), putting learning into context (64.2\%), applying experience to real life (69.0\%), and working through the process of figuring something out (72.3\%). Here, moving beyond usage statistics alone, we can see that those students who 


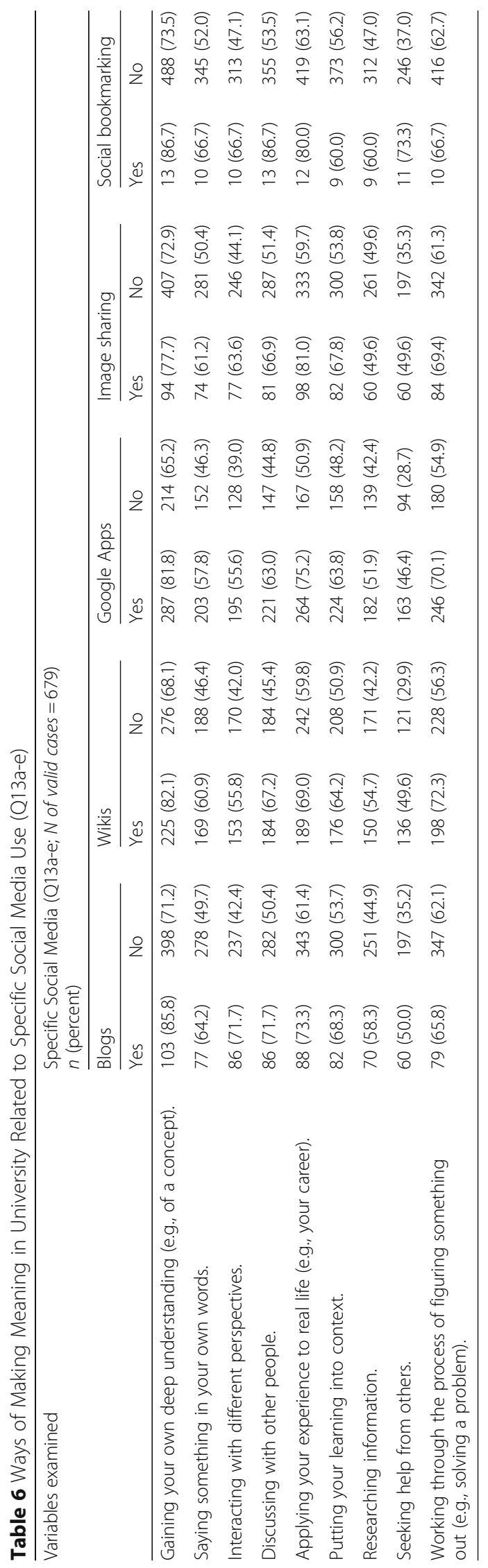




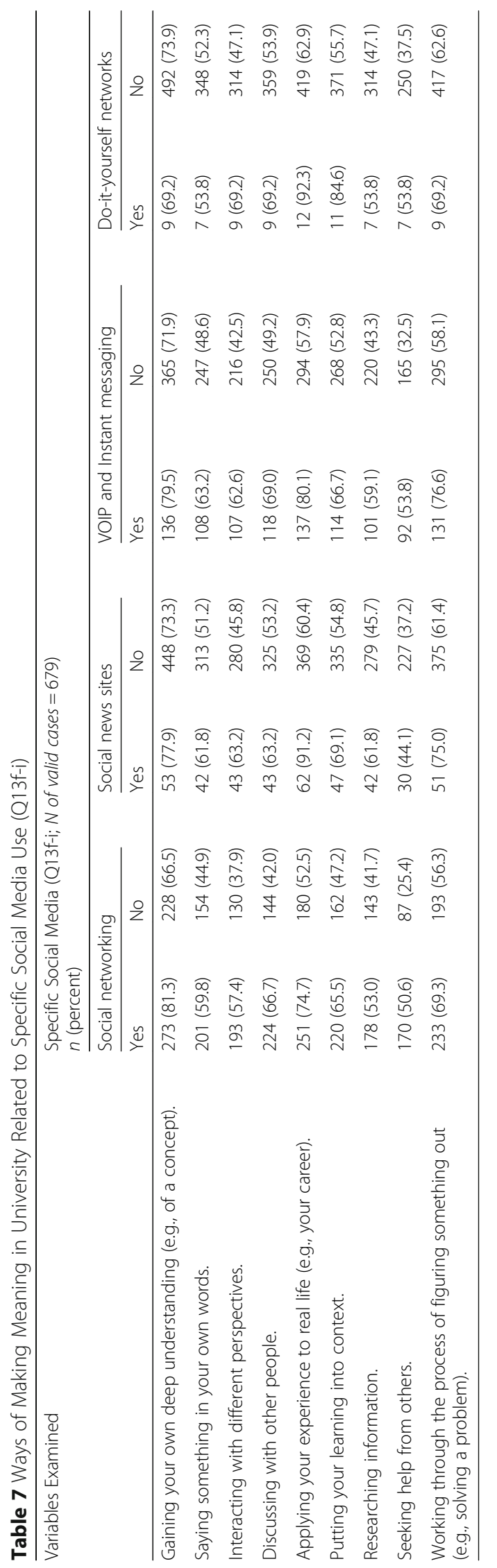




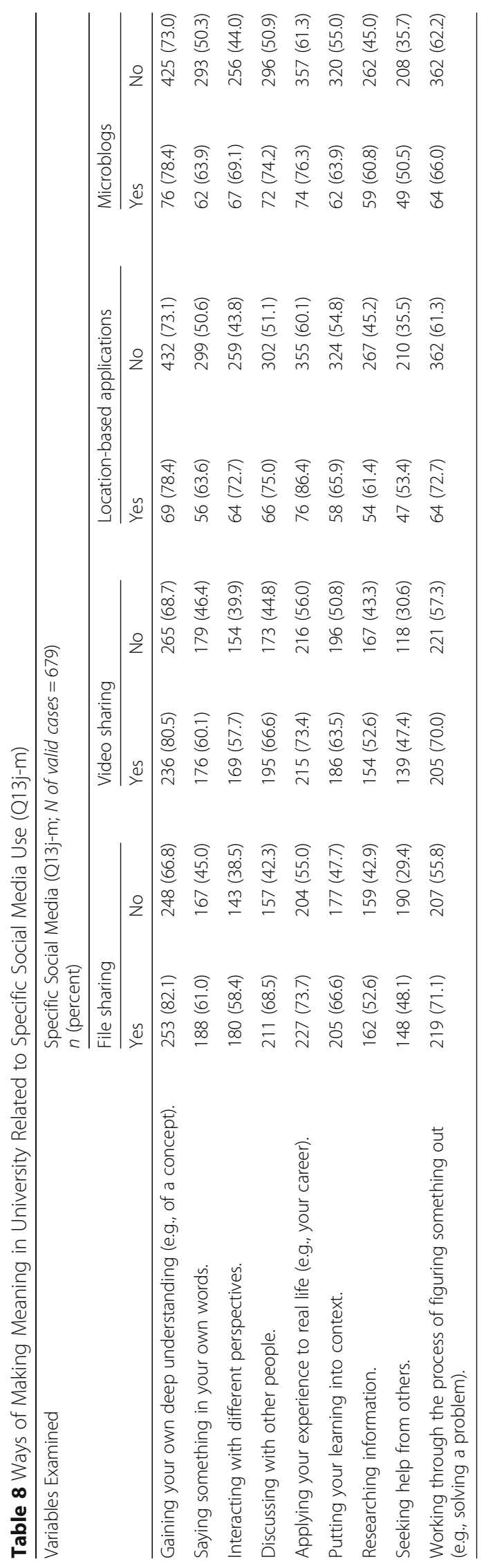


indicated using wikis also indicated that they engage in a diverse range of meaning making activities, from discussing with others to putting learning into context and solving a problem.

Further insights into less popular SMTs are also revealed when considering meaning making. For instance, VOIP and instant messaging were the sixth most used SMT, reported by only $25.2 \%$ of students (see Fig. 1 ). However, students who used VOIP and instant messaging in their learning also indicated that they engaged in the entire range of meaning making activities listed, including researching information (59.1\%), seeking help from others $(53.8 \%)$, saying something in your own words (63.2\%), applying experience to real life (80.1\%), and so on (see Table 7). There are connections for a range of meaning making activities related to other less frequently used SMTs, including image sharing, blogs, microblogs, location-based applications, and social news sites. Unsurprisingly, those SMTs that had very low use - social bookmarking (2.2\%) and do-it-yourself networks (1.9\%) - also had fewer associations with meaning making activities. For the small percentage of students who did use these technologies, instead of a range of meaning making activities there were one or two specific meanings present, with connections between social bookmarking and seeking help from others, as well as do-it-yourself networks and applying experience and putting learning into context (see Tables 6, 7, and 8). These results were consistent with the interview results, where no students indicated use of or familiarity with do-it-yourself networks, and very few were familiar with social bookmarking. The interviews and survey responses both showed very low usage and understanding of do-it-yourself networks and social bookmarking, and as a result those items have been removed from the updated categories of social media since they were not commonly known or used by post-secondary learners in this study, shown below. Informed by the data analysis, the following outlines the updated and validated list of social media categories in university learning:

\section{Updated categories of social media for undergraduate learning}

1. Google Apps (e.g., Google Calendar, Google Docs)

2. Social networking (e.g., Facebook)

3. File sharing (e.g., Dropbox, Google Drive, BitTorrent)

4. Video sharing (e.g., YouTube, Vine)

5. Wikis (e.g., Wikipedia, Wikimedia)

6. VOIP/instant messaging (e.g., Skype, Google Talk/Chat)

7. Image sharing (e.g., Flickr, Instagram, Pinterest)

8. Blogs (e.g., Blogger, WordPress)

9. Microblogs (e.g., Twitter)

10. Location-based apps (e.g., Foursquare, Google Maps)

11. Social news sites (e.g., Reddit)

As social media evolve and change, it will be important for future studies not only to continue updating and validating specific categories of social media, but also to confirm whether and how broader groupings of the affordances of social 
media (i.e., the affordances related to the social media characteristics) may remain or change over time.

\section{Characteristics of social media for undergraduate learning}

Another key contribution of this study is the creation and validation of characteristics of social media for undergraduate learning, providing further insights into what these social media afford in undergraduate learning, and tied to the discussion of why students may choose to use certain social media over others. Responses for social media characteristics that are useful and help to make meaning of university learning (Q15 means ranging from 1.51 to 2.70 and Q16 means ranging from 1.78 to 2.68; see Tables 10 and 11 in Appendix) were higher overall as compared to those provided for the importance of particular SMTs (Q14 means ranging from 1.71 to 3.59; see Table 9 in Appendix). In other words, there were generally higher mean rankings for these characteristics of social media than for the importance of specific SMTs themselves. When connected to notions of affordances, this reinforces that students generally gave higher agreement for these characteristics of social media as being useful and helping to make meaning of their university learning, rather than for the importance of specific SMTs themselves. Demonstrating further the activities and interactions that students most commonly reported with SMTs, for the validated characteristics of social media for undergraduate learning, the results are based on characteristics frequently identified (listed from highest to lowest means):

\section{Characteristics of social media for undergraduate learning}

1. Collaborating to create documents online;

2. Sharing information online;

3. Tracking and managing your academic schedule;

4. Building relationships with peers;

5. Posting/re-posting media or information found online;

6. Creating media to share online;

7. Commenting on media or information found online.

The characteristic related to building relationships with instructors investigated in the study was removed from the above listed based on quantitative and qualitative findings, which emphasized student-student and student-content interactions on social media but problematized the use of social media for faculty-student interactions (for more information, see Smith, 2016a; 2016b).

\section{Social media and meaning making}

As the Pearson correlation demonstrates, there is a relationship between the ways of making meaning and specific social media technologies used in undergraduate learning, demonstrating that, from the learners' perspective, it is important to fully consider why, how, and what types of interactions occur via SMTs in their undergraduate learning. Associations between particular ways of making meaning and specific SMTs also revealed interesting patterns in the meaning making activities outlined. As an 
example, for gaining a deeper understanding (e.g., of a concept), a high number of connections existed with blogs, wikis, Google Apps, social networking, file sharing, and video sharing, as well as VOIP/instant messaging (see Tables 6, 7, and 8). Conversely, there are few or no connections between gaining a deeper understanding and use of image sharing, social news sites, location-based applications, or microblogs. These findings are consistent with the interviews, where many students stated that the limitations or specific functions of tools such as Twitter, Instagram, and Google Maps meant that it was often difficult to gain a deep conceptual understanding from using them. While many students indicated that these SMTs did serve a useful purpose (e.g., Google Maps was useful for directions and finding places), their design and functions were often viewed as not helping to build deep conceptual understandings for their university studies. Yet the opposite is true for other purposes such as applying experiences to real life (e.g., a career), researching information, and interacting with different perspectives, where such meaning making activities are associated with microblogs and location-based applications. This reinforces what several students articulated during the interviews: perceptions and uses of social media are associated with the meaning, context, and the purpose at hand.

Notably, the survey revealed that $71.5 \%(n=451)$ of respondents do use social media in their own university learning. Contrary to Kennedy et al.'s (2007) earlier research showing social media use for collaboration and self-publishing in this generation to be quite low, this study demonstrates that today a large number of undergraduate students do use social media as a part of their learning, including for collaborative interactions. Interview results revealed that students value social media in their own learning not only for social interaction and online collaboration, but also for information finding and individual study or review (Smith, 2016a). During the interviews, students commonly placed importance on online file sharing and document collaboration tools, social networking via SMTs, and building their understanding of core concepts by viewing online videos and wikis, etc. This finding is confirmed by survey results showing the most commonly used SMTs (outlined in Fig. 1) are those enabling collaboration with peers. Online file collaboration and sharing (e.g., the institutional version of Google Docs) and social networking technologies (e.g., Facebook) are the top SMTs students reported using for collaborating in their university learning. However, video sharing services such as YouTube (e.g., Khan Academy), and wikis (e.g., Wikipedia) are also a top choice, with interviews revealing that such SMTs are often used for individual learning and review of concepts.

\section{Recommendations}

Based on these findings, several recommendations emerge, including implications for pedagogy in practice and priorities for future research studies.

\section{Understanding the meaning of meaningful}

Meaning making is frequently mentioned in reference to education, and the "meaning of meaningful interaction" is strongly related to learning theories (Woo \& Reeves, 2007, p. 16). Yet, often while invoking the term "meaningful learning," researchers and practitioners fail to provide a clear definition for what constitutes 
"meaningful" interactions within learning. For example, while frequently using the term "meaningful" in their creation of a model for e-learning in Canada (called the Meaningful E-Learning Project, or MEL), Salyers, Carter, Carter, Myers, and Barrett (2014) discussed in detail the term e-learning, but do not provide any definition or context for what constitutes meaningful learning. Here again, from a deterministic view, the focus is on the effectiveness of technology and on defining e-learning, ignoring the key issue of what it means to be meaningful. This study illustrates a significant relationship between ways of making meaning and specific social media technologies used in learning, and a main implication and recommendation related to this finding is the need to continue to grow a shared understanding of meaningful learning interactions via technology, particularly from the perspective of undergraduate students.

This study is framed within a social constructivist approach, since alignment between the affordances of social media and the premises of social constructivist learning theories (Dron \& Anderson, 2014) are well established. As reflected in Anderson's (2008) equivalency theorem, many thinkers connect deep learning to meaningful learning (for more information on educational interactions and social media, see Smith, 2016b). However, while there is much rigorous research on deep versus surface approaches to learning (e.g., Trigwell, Prosser, \& Waterhouse, 1999), as Woo and Reeves (2007) aptly showed, the meaning of meaningful learning is necessarily relative in that it depends upon how we understand learning itself, as reflected in learning theories. This reinforces the importance of framing technological affordances for meaningful educational interactions, such as those presented via the core categories and characteristics of social media in this study, with explicit connections to how learning is understood and to research-informed theoretical groundings. Such links between research and practice can also build educators' and administrators' research-informed understandings of undergraduate perspectives and uses of social media in their university learning, with the ultimate goal of supporting evidence based decision-making in higher education policy and practice. The findings presented in this study reinforce a need for further research on learning and technology that engage and explain undergraduates' understanding of meaning making explicitly, including the particular ways in which social-technological interactions via social media and other emerging educational technologies inform and reflect meaning making processes in undergraduate learning.

\section{Building digital literacies}

Since many students indicated that they use social media in their own undergraduate learning, even while there is reluctance to include SMTs in the formal curriculum (Jones et al., 2010; Sehatzadeh \& Le-May Sheffield, 2014), a key recommendation of this study is to teach essential digital literacies that allow students to navigate the complexities of social media as a part of a comprehensive undergraduate education. Digital literacies are defined as "the ability to use information and communication technologies to find, evaluate, create, and communicate information, requiring both cognitive and technical skills" (ALA Digital Literacy Taskforce, 2011, para 2). Koltay illustrates the importance of these literacies, noting that "[m]edia literacy, information literacy and digital literacy are the 
three most prevailing concepts that focus on a critical approach towards media messages" (2011, p. 211).

A majority of students indicated that they are using social media in their own learning, and developing students' knowledge and skills with regard to wider digital literacies could foster their abilities for integrating beneficial aspects of social media that can help their learning, while also mitigating the drawbacks that can hinder learning (Smith, 2016a; 2016b). Recent ECAR findings show that students today do not feel better prepared to use technologies than in prior years. Rather, undergraduates reported that they could use technologies such as social media more effectively for learning if they were more skilled at their application and use (Dahlstrom et al., 2015). Reinforcing these results, students in this study also expressed their need to further understand why and how certain SMTs can be used for learning in meaningful ways. Several models for building digital literacies are evolving (e.g., Littlejohn, Beetham, \& McGill, 2012; O’Neil, 2014), providing post-secondary institutions with frameworks to teach students the digital literacies needed for navigating social media in ways that can facilitate their learning even if SMTs are separate from the formal curriculum. Engaging with digital literacies, future research connected to practice can develop our understandings of meaningful use of SMTS and inform strategies to effectively teach undergraduates such cognitive and technical skills across the curriculum.

\section{Conclusion}

Addressing calls to move beyond the digital native debate by providing researchinformed understandings of Net generation students in context, this study illustrates the SMTs students use in their learning and the relationship between social media and a variety of meaning making activities. There is a significant relationship between particular ways of making meaning and specific social media use, giving much-needed context to students' perceptions and uses of SMTs in learning. These findings provide new insights into why and how undergraduates choose (or, choose not) to use SMTs outside of the formal curriculum.

Overall, the qualitative and quantitative findings in this study emphasize that while general ideas of meaning making and use of social media are often similar for undergraduate students across disciplines, delving further into their specific ways of making meaning and the specific uses of social media in context illustrates a number of important relationships and differences between undergraduates when considered in context. Since social media change rapidly, knowing the underlying and persisting characteristics that enable meaningful learning provides opportunities to leverage the affordances that support individual study and collaborative learning in higher education. As social media continue to emerge and change over time, it is imperative to know the interactions that students view to be meaningful, and the reasons why they choose to use (or, not use) such technologies in their own learning. Knowing what is afforded within social media categories and characteristics, and therefore why certain technologies may be valued by students, gives a fuller picture of the purpose and function of social media for university learning, from the students' perspective. While meaningful educational interactions can occur via social media, the decision whether or not to use social media in learning depends on careful consideration of what is afforded, giving equal consideration to both what is lost and what is gained. 


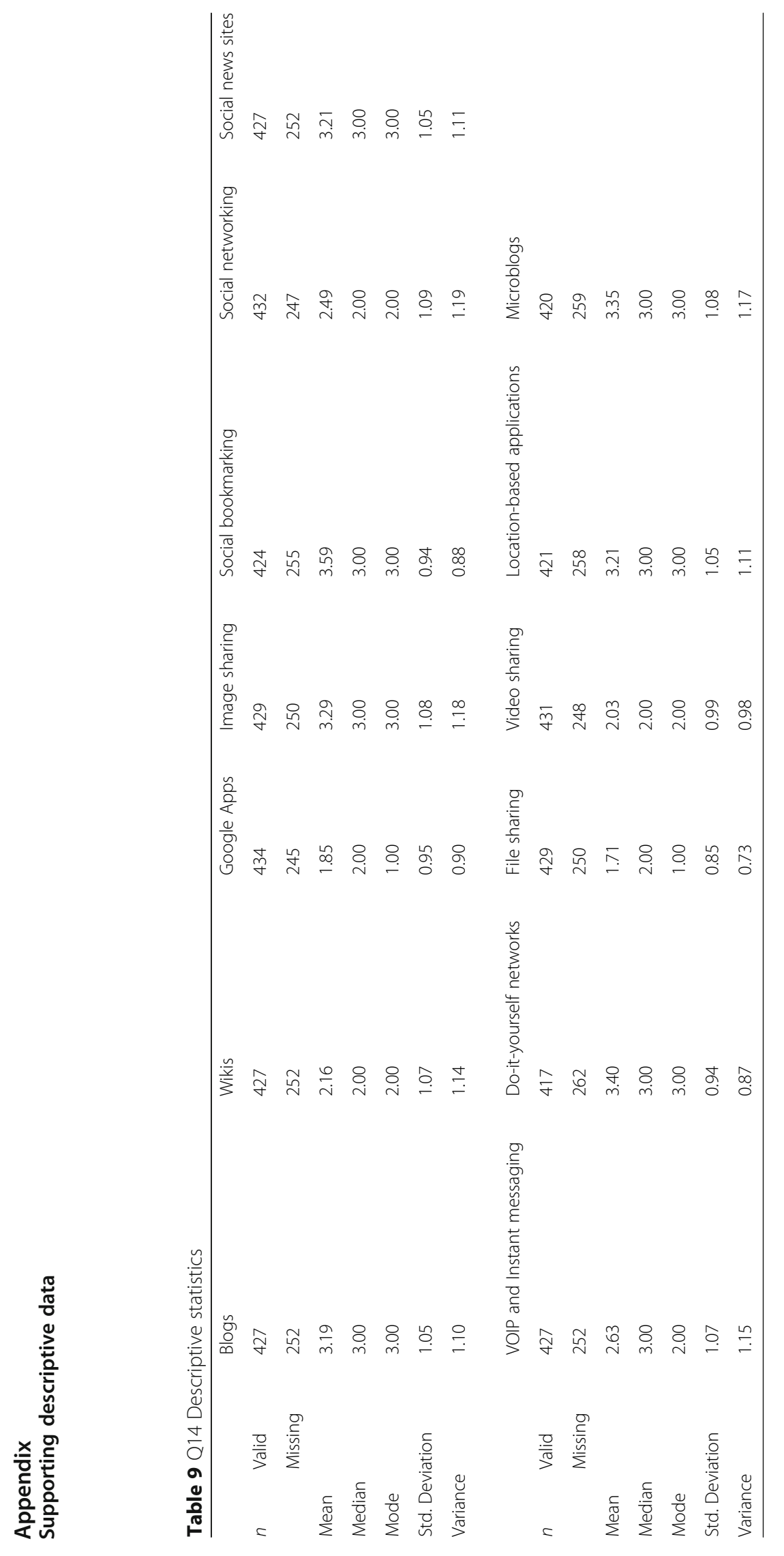




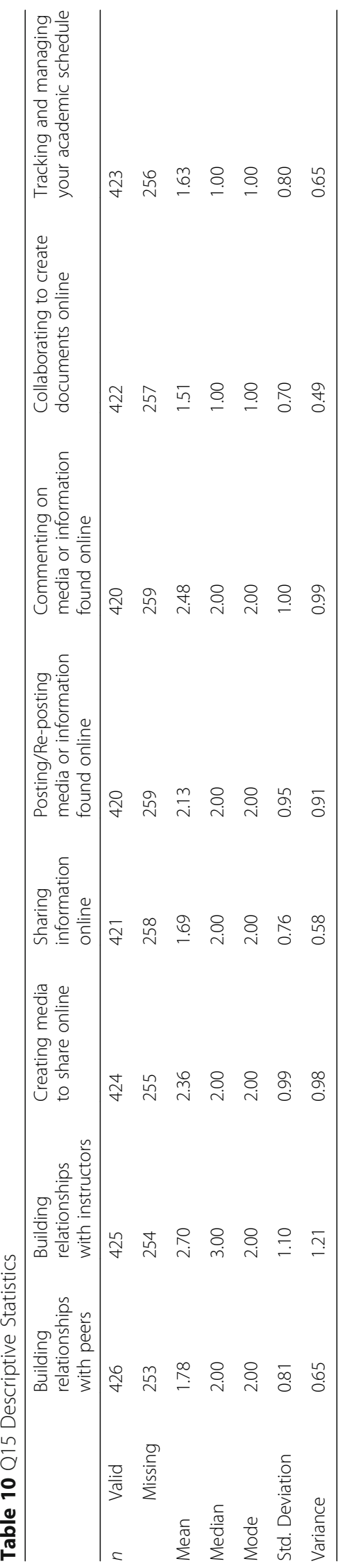




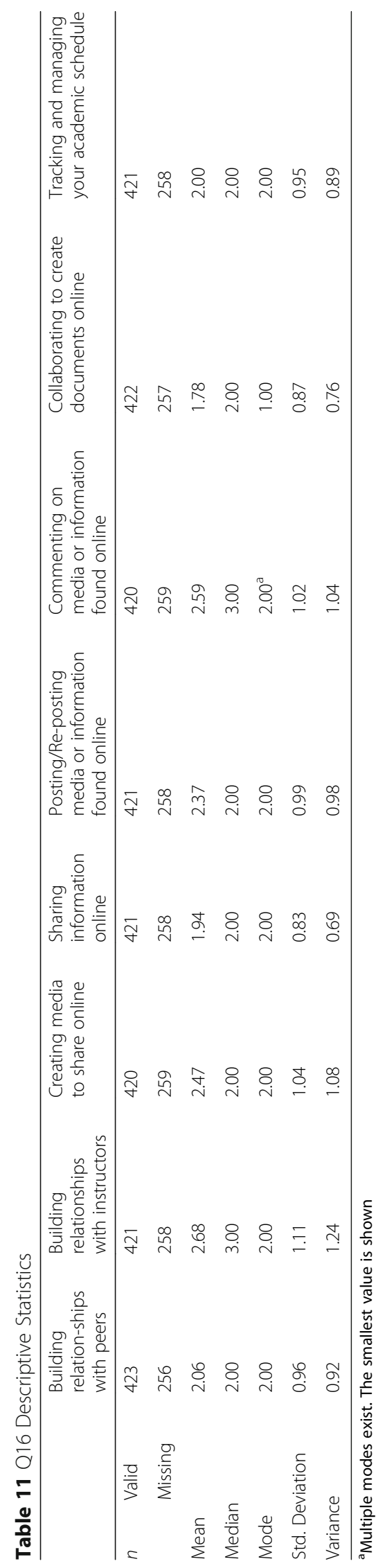




\section{Additional file}

Additional file 1: Survey Instrument. (DOC $502 \mathrm{~kb}$ )

\section{Acknowledgements}

This research was supported by the Social Sciences and Humanities Research Council of Canada (reference number 752-2013-1225), and was completed as a part of the author's doctoral thesis, supervised by Dr. Heather Kanuka.

\section{Availability of data and materials}

Supplementary data analysis and information is available in the author's full dissertation file, which is accessible via an open online repository at: http://hdl.handle.net/11205/271.

\section{Competing interests}

The author declares that he/she has no competing interests.

Received: 22 June 2016 Accepted: 14 February 2017

Published online: 07 April 2017

\section{References}

ALA Digital Literacy Taskforce. (2011). What is digital literacy? Retrieved from http://connect.ala.org/node/181197.

Anderson, T. (2008). Towards a theory of online learning. In T. Anderson (Ed.), The theory and practice of online learning (2nd ed., pp. 45-74). Retrieved from http://www.aupress.ca/index.php/books/120146.

Bennett, S., \& Maton, K. (2010). Beyond the 'digital natives' debate: towards a more nuanced understanding of students' technology experiences. Journal of Computer Assisted Learning, 26(5), 321-331. http://dx.doi.org/10.1111/j.1365-2729.2010.00360.x

Buckingham, D. (2011). Foreword. In M. Thomas (Ed.), Deconstructing digital natives: young people, technology and the new literacies (pp. iv-xi). New York, NY: Routledge.

CBC News. (2015). Dalhousie dentistry report: University had culture of 'misogyny, homophobia and racism'. Canadian Broadcasting Corporation. Retrieved from http://www.cbc.ca/news/

Charmaz, K. (2014). Constructing grounded theory (2nd ed.). Los Angeles: Sage.

Cohen, L., Manion, L., \& Morrison, K. (2011). Research methods in education (7th ed.). New York, NY: Routledge.

Colton, T. (1974). Statistics in medicine. Boston, MA: Little, Brown \& Co.

Creswell, J. W. (2014). Research design: qualitative, quantitative, and mixed methods approaches (4th ed.). Thousand Oaks, CA: Sage Publications, Inc.

Dahlstrom, E. (2012). ECAR study of undergraduate students and information technology, 2012. EDUCAUSE Center for Applied Research, Retrieved from http://net.educause.edu/ir/library/pdf/ERS1208/ERS1208.pdf.

Dahlstrom, E., \& Bichsel, J. (2014). ECAR study of undergraduate students and information technology, 2014. EDUCAUSE Center for Applied Research, Retrieved from http://net.educause.edu/ir/library/pdf/ss14/ERS1406.pdf.

Dahlstrom, E., Brooks, C. D., Grajek, S., \& Reeves, J. (2015). ECAR study of undergraduate students and information technology, 2015. EDUCAUSE Center for Applied Research, Retrieved from https://net.educause.edu/ir/library/pdf/ss14/ERS1406.pdf.

Driscoll, M. (2005). Psychology of learning for instruction (3rd ed.). Boston, MA: Pearson Education, Inc.

Dron, J., \& Anderson, T. (2014). Teaching crowds: learning and social media. Retrieved from http://www.aupress.ca/ index.php/books/120235.

Hamid, S., Waycott, J., Kurnia, S., \& Chang, S. (2015). Understanding students' perceptions of the benefits of online social networking use for teaching and learning. The Internet and Higher Education, 26, 1-9. http://dx.doi.org/10.1016/j.iheduc.2015.02.004.

Hayman, R., \& Smith, E. E. (2015). Sustainable decision making for emerging educational technologies in libraries. Reference Services Review, 43(1), 7-18. http://dx.doi.org/10.1108/RSR-08-2014-0037.

Herrington, J., Reeves, T. C., \& Oliver, R. (2010). A guide to authentic e-learning. New York, NY: Routledge.

Jones, N., Blackey, H., Fitzgibbon, K., \& Chew, E. (2010). Get out of MySpace! Computers \& Education, 54(3), 776-782. http://dx.doi.org/10.1016/j.compedu.2009.07.008.

Kennedy, G. E., Dalgarno, B., Gray, K., Judd, T. S., Waycott, J., Bennett, S. J., ...Churchwood, A. (2007). The Net generation are not big users of Web 2.0 technologies: Preliminary findings. In ICT: Providing choices for learners and learning. Proceedings Ascilite Singapore 2007. Retrieved from http://ro.uow.edu.au/edupapers/920/

Kennedy, G., Dalgarno, B., Bennett, S., Gray, K., Waycott, J., Judd, T., ...Chang, R. (2009). Educating the net generation. A handbook of findings for practice and policy. Retrieved from https://www.griffith.edu.au/__ data/assets/pdf_file/0003/155973/NetGenHandbookAll.pdf

Kennedy, G. E., Judd, T. S., Dalgarno, B., \& Waycott, J. (2010). Beyond natives and immigrants: exploring types of net generation students. Journal of Computer Assisted Learning, 26(5), 332-343. http://dx.doi.org/10.1111/j.1365-2729.2010.00371.x.

Koltay, T. (2011). The media and the literacies: media literacy, information literacy, digital literacy. Media, Culture \& Society, 33(2), 211-221. http://dx.doi.org/10.1177/0163443710393382.

Littlejohn, A., Beetham, H., \& McGill, L. (2012). Learning at the digital frontier: a review of digital literacies in theory and practice. Journal of Computer Assisted Learning, 28(6), 547-556. http://dx.doi.org/10.1111/j.1365-2729.2011.00474.x.

Merriam, S. B. (2009). Qualitative research: a guide to design and implementation. San Francisco, CA: Jossey-Bass.

Mezirow, J. (1991). Transformative dimensions of adult learning. San Francisco, CA: Jossey-Bass.

O'Neil, M. (2014). Confronting the myth of the 'digital native.'. The Chronicle of Higher Education, Retrieved from http://chronicle.com/.

Postman, N. (1992). Technopoly: the surrender of culture to technology. New York, NY: Random House, Inc. 
Saeed, N., Yun, Y., \& Sinnappan, S. (2009). Emerging web technologies in higher education: a case of incorporating blogs, podcasts and social bookmarks in a web programming course based on students' learning styles and technology preferences. Journal of Educational Technology \& Society, 12(4), 98-109. http://www.ifets.info/.

Salyers, V., Carter, L., Carter, A., Myers, S., \& Barrett, P. (2014). The search for meaningful e-learning at Canadian universities: A multi-institutional research study. The International Review of Research in Open and Distributed Learning. Retrieved from http://www.irrodl.org/index.php/irrodl

Sehatzadeh, A., \& Le-May Sheffield, S. (2014). Survey of faculty use of online technologies 2013. Retrieved from https://www.dal.ca/ content/dam/dalhousie/pdf/dept/clt/e-learning/Faculty\%20Write\%20up\%20for\%20dissemination_FINAL_Sept_29.pdf.

Selwyn, N. (2012). Making sense of young people, education and digital technology: the role of sociological theory. Oxford Review of Education, 38(1), 81-96. http://dx.doi.org/10.1080/03054985.2011.577949.

Smith, E. E. (2012). The digital native debate in higher education: A comparative analysis of recent literature. Canadian Journal of Learning and Technology, 38(3). http://dx.doi.org/10.21432/T2F302.

Smith, E. E. (2016a). Exploring undergraduate perceptions of meaning making and social media in their learning (Doctoral thesis, University of Alberta, Edmonton, Canada). Retrieved from: http://hdl.handle.net/11205/271.

Smith, E. E. (2016b). "A real double-edged sword:" Undergraduate perceptions of social media in their learning. Computers \& Education, 103, 44-58. http://dx.doi.org/10.1016/j.compedu.2016.09.009.

Smith, E. E., \& Hayman, R. (2016). Decision-making and problems of evidence for emerging educational technologies. In. (P. Newton, \& D. Burgess, Eds.), The best available evidence: Wise decision-making for educational improvement (pp. 147-166). Sense Publishers.

Statistics Canada. (2011). Education in Canada: Attainment, field of study and location of study. Statistics Canada Catalogue no. 99-012-X2011001. Retrieved from http://www12.statcan.gc.ca/nhs-enm/2011/as-sa/99-012-x/99-012x2011001-eng.cfm

Trigwell, K., Prosser, M., \& Waterhouse, F. (1999). Relations between teachers' approaches to teaching and students' approaches to learning. Higher Education, 37(1), 57-70. http://dx.doi.org/10.1023/A:1003548313194.

Valtonen, T., Dillon, P., Hacklin, S., \& Vaisanen, P. (2010). Net generation at social software: challenging assumptions, clarifying relationships and raising implications for learning. International Journal of Educational Research, 49, 201-219. http://dx.doi.org/10.1016/j.jer.2011.03.001

Willcockson, I. U., \& Phelps, C. L. (2010). Keeping learning central: a model for implementing emerging technologies. Medical Education Online, 15, 1-6. http://dx.doi.org/10.3402/meo.v15i0.4275.

Woo, Y., \& Reeves, T. C. (2007). Meaningful interaction in web-based learning: a social constructivist interpretation. The Internet and Higher Education, 10(1), 15-25. http://dx.doi.org/10.1016/j.iheduc.2006.10.005.

Woolfolk, A. E., Winne, P. H., Perry, N. E., \& Shapka, J. (2010). Educational psychology (4th ed.). Toronto: Pearson Canada.

\section{Submit your manuscript to a SpringerOpen ${ }^{\circ}$ journal and benefit from:}

- Convenient online submission

- Rigorous peer review

- Immediate publication on acceptance

- Open access: articles freely available online

- High visibility within the field

- Retaining the copyright to your article

Submit your next manuscript at $\boldsymbol{~ s p r i n g e r o p e n . c o m ~}$ 